\title{
Power-to-gas plants and gas turbines for improved wind energy dispatchability: Energy and economic assessment
}

\author{
Giulio Guandalini *, Stefano Campanari, Matteo C. Romano
}

Politecnico di Milano, Department of Energy, via Lambruschini 4A, 20156 Milano, Italy

\begin{abstract}
Limited dispatchability of wind parks and unexpected grid power injections create unbalances between the generated electric power and the actual required power that has to be reduced for proper operation of the electrical grid. The increasing amount of renewable energy sources stresses this problem in several countries, where the responses in terms of reinforcement of transmission lines and ancillary services are not sufficiently fast or effective. In this study, we analyze the potential of a grid balancing system based on different combinations of traditional gas turbine based power plants with innovative 'power-to-gas' plants. Power-to-gas is a promising solution to balance the electric grid, based on water electrolysis, which can effectively contribute to reducing the uncertainty of dispatch plans. According to this sys-tem, the excess power produced by renewables is converted into hydrogen, which can be then injected into the natural gas grid. Different economic scenarios are assessed in this work, leading to a set of opti-mal sizes of the proposed system, using a statistical approach in order to estimate wind farm productivity and forecasting errors, as well as each component load conditions. Economic parameters, equivalent operating hours, $\mathrm{CO}_{2}$ emissions and lost wind energy are the main performances indexes considered in this work to compare gas turbine and electrolysis balancing systems. From an economic point of view, hybrid systems including both balancing technologies generally lead to the best performances. The scenario which leads to the highest power-to-gas capacity (with installed electrolysis power of about $6 \%$ of wind park nominal power) is determined coupling a mid-term perspective of reduction in investment costs with favorable energy market conditions or with incentives ("green-gas" or carbon taxes). In such conditions, an equivalence between the two technologies in terms of optimum installed power can be reached at an electricity-to-natural gas cost ratio between 1.8 and 2 . In most interesting scenarios, the P2G system brings about a lower total wind electricity injected in the grid, due to wind-to-gas energy conversion, while it allows reducing energy losses due to grid congestion and curtailment of the wind park; however, the additional $\mathrm{CO}_{2}$ emissions due to gas turbines operation and due to the reduced electricity production tend to offset or to limit the positive effect of the carbon-free gas production.
\end{abstract}

\section{Nomenclature}

AD aero-derivative gas turbine

CAES compressed air energy storage

CSP concentration solar plant

EL electrolysis-based balancing system

GT gas turbine-based balancing system

HD heavy duty gas turbine

NG natural gas

PEM polymeric electrolyte fuel cell

PHS pumped-hydro storage

\author{
P2G power-to-gas \\ PV photo-voltaic \\ TSO transmission system operator
}

Subscripts

el electric

disp dispatched

min minimum

max maximum

\footnotetext{
* Corresponding author. Tel.: +39 0223993935.

E-mail addresses: giulio.guandalini@polimi.it (G. Guandalini), stefano. campanari@polimi.it (S. Campanari), matteo.romano@polimi.it (M.C. Romano).
} 


\section{Introduction}

Renewable energy share is continuously increasing in most of the industrialized countries, allowing environmentally friendly power production but entailing growing issues in power grids management $[1,2]$. Power generation by fossil fuel power stations,

traditionally used for balancing purpose together with pumpedhydro plants, can hardly compensate power output fluctuations of increasing number of power plants based on non-predictable energy sources, especially wind and PV technologies. The resulting increasingly fluctuating operations required to traditional plants and their lower efficiency at partial load, reduce the availability of balancing reserve and add pressure on shrinking power plant operational margins [1]. In IEA Energy Technology Perspectives for the 2050 [3], the share of renewables is forecasted at $57-71 \%$ of the global electricity production if international community will pursue a strong $\mathrm{CO}_{2}$ emissions reduction policy ("2DS" and " $2 D S$ HiRen" scenarios). Otherwise, a reference scenario ("4DS") limits the expected contribution of renewables to $36 \%$. In this work, we are interested in the increasing share of wind and solar power which are nowadays covering the majority of power in new renewables installations. Their production is well-known as nondispatchable with the current technology (except for CSP solar plants with thermal storage, which are however currently marginal with respect to wind and PV). A large effort has been devoted in the last years in finding solutions capable of mitigating the effects of the oscillation of non-dispatchable generated power on the quality and reliability of the electricity service $[1,4,5]$.

A first option is the adoption of a more flexible generation system involving traditional technologies with improved start-up and load following capabilities. According to this viewpoint, flexible combined cycle power plants layouts are being developed [6,7] and a higher number of simple GT cycles might be introduced in the generation park [8].

Additionally, in order to face the challenges of larger presence of unpredictable renewables, energy storage systems (ES) are currently developed and many solutions are already available [9-14]. Among them, pumped-hydro storage (PHS) plants are well known to provide fast power balancing. However, the possibility to install large hydro plants is limited by the availability of attrac-tive sites depending on the geographical location, as well as by environmental impact and social acceptance issues, so that in most countries it is not considered feasible to deploy very large new hydro plant installations in the mid-term future [15]. Anyway, in the next future (2050 horizon), PHS installed capacity in EU countries could reach up to $91-188 \mathrm{GW}$, depending on the scenario, due to new plants installation or repowering of the existing fleet (current European installed PHS capacity is about $40 \mathrm{GW}$ ) [16,17]. Compressed air energy storage plants (CAES) are also considered as an alternative option [3,12], although similar issues of site availability exist, and the technology has been demonstrated in a few cases (i.e. Huntorf, Germany, 1978, $290 \mathrm{MW} / 870 \mathrm{MW}$ h [18]; Mcintosh, USA, 1991, $110 \mathrm{MW} / 2.8 \mathrm{GW}$ h [19]).

Within ES technologies, another possibility is the development of electrical energy storage technologies (EES), including batteries, supercapacitors and flywheels which are particularly suitable for frequency and voltage control on fast time scales. Nevertheless, only a limited number of EES (e.g. some kind of electrochemical batteries or flow batteries) can contribute in reducing massive transmission curtailment, providing load following and time shifting capabilities that can require long term storage (minutes to days).

An alternative research field involves hydrogen-based energy storage systems (HES), adopting electrolysis devices, which are nowadays considered a promising solution to support PHS and CAES $[9,20,21]$.

In addition to the possibility of storing hydrogen for subsequent electricity production or other uses, e.g. feeding refueling stations for hydrogen vehicles, HES systems can be developed with the scope of injecting hydrogen (at limited percentages) in the existing natural gas infrastructure, according to an approach which has been recently receiving attention $[21,22]$. The aim of such system is to handle large electrical power fluctuations by providing negative balancing power and exploiting the excess energy otherwise curtailed, avoiding issues and costs due to a local hydrogen storage and reconversion. This solution is usually known as "power-togas" (P2G). Various layouts can be adopted, according to the electrolysis technology (alkaline or PEM) and to the additional possible introduction of a methanation process to convert hydrogen into synthetic methane before pipeline injection.

The aim of this paper is to evaluate the potential of power-togas technology as energy balancing system on an economic, energy and environmental basis, in order to estimate its effectiveness in balancing the power produced by a large group of wind farms, interconnected to the national grid of a European country $[23,24]$. In a previous work [25] the authors have assessed the potential of P2G compared to a traditional balancing system based on gas turbines, considering the two systems separately. In this paper, we explore how the power-to-gas concept can be effectively coupled and integrated with a balancing system exploiting a fleet of gas turbine plants: the two systems are working on opposite operating principles, so that a positive synergy can be expected. The comparison is made considering different sizes of the two balancing systems, optimized for various economic scenarios on the basis of a common statistical approach for the expected errors in wind forecast.

\section{Power-to-gas concept}

As anticipated, Power-to-gas technologies consist in producing pure hydrogen by water electrolysis and injecting it into the natural gas infrastructure, directly or after upgrading to synthetic methane. The approach considered in this work is the first, which does not require integration with a $\mathrm{CO}_{2}$ source required for the methanation process. In principle, this kind of plant is based on well-known technologies as alkaline water electrolyzers gas transport infrastructure components. Nevertheless, in order to follow the fluctuations of non-dispatchable renewable sources, 
improvement of transients and off-design efficiency with respect to the available commercial electrolyzers is required. As a matter of fact, electrolyzers are today usually designed for process hydro-gen production at steady state and nominal load. Moreover, a reduction in the cost is desired to improve the competitiveness with respect to other storage technologies. Development of pres-surized devices is another key aspect, since a sufficiently high pres-sure allows the direct hydrogen injection into the pipelines without needing additional $\mathrm{H}_{2}$ compression.

Many demonstration scale projects have been developed in the past related to energy storage in form of hydrogen, mainly in isolated grids $[26,27]$. Most of them include a local hydrogen conversion back to electricity. Few projects include the idea of mixing hydrogen with natural gas. Recently, this last option has been reconsidered and demonstration plants have been built in Germany (i.e. Falkenhagen, 2013 [28], $2 \mathrm{MW}, 360 \mathrm{~N} \mathrm{~m}_{\mathrm{H} 2}^{3} / \mathrm{h}$ ). Many projects [22] are currently developing this research field, such as INGRID (EU, [29]), GRHYD (France, [30]) and GRIDGAS (UK, [31]).

The interest in this solution is supported by some simple considerations regarding the potential of the long-term, large scale energy storage capacity given by the natural gas grid. Some estimates are reported in Table 1 for representative European countries based on the size of the actual NG annual market and on an average efficiency of the process [32].

For instance, considering to inject in the distributed natural gas an amount of hydrogen corresponding to $1 \mathrm{vol} \%$ on an average annual basis, from Table 1 it is possible to see how the corresponding energy consumption (i.e. the amount of electrical energy 'storable') is in some countries above $10 \%$ of total wind + solar production, a value expected to be high enough to mitigate the production instability of very large wind parks.

Table 1

NG transport capacity in some countries and corresponding electricity consumption for injecting $1 \mathrm{vol} \%$ hydrogen on an average annual basis, compared with current wind + solar production.

\begin{tabular}{llcc}
\hline & $\begin{array}{l}\text { NG transport } \\
\left(\times 10^{9} \mathrm{~N} \mathrm{~m}^{3} / \mathrm{y}\right)^{\mathrm{a}}\end{array}$ & $\begin{array}{l}\text { Electricity for } \\
1 \text { vol\% } \mathrm{H}_{2}\left(\mathrm{TW} \mathrm{h}_{\mathrm{el}} /\right. \\
\mathrm{y})^{\mathrm{b}}\end{array}$ & $\begin{array}{l}\text { Total electricity from } \\
\text { wind }+ \text { solar }\left(\mathrm{TW} \mathrm{h}_{\mathrm{el}} / \mathrm{y}\right)^{\mathrm{c}}\end{array}$ \\
\hline Germany & 85 & 4.4 & 79.7 \\
Italy & 78 & 4.0 & 31.5 \\
Spain & 34 & 1.7 & 57.7 \\
UK & 83 & 4.3 & 23.5 \\
U.S. & 690 & 35.4 & 142.0 \\
Japan & 121 & 6.2 & 13.3 \\
\hline
\end{tabular}

a Data from IEA Gas Market Report 2012 [33] (Ref. year 2011).

b With $60 \%$ efficiency $\left(\mathrm{H}_{2, \mathrm{LHV}} / \mathrm{E}_{\mathrm{el}}\right)$.

c Data from IEA Renewable Energy Market Report 2012 [34] (Ref. year 2012).

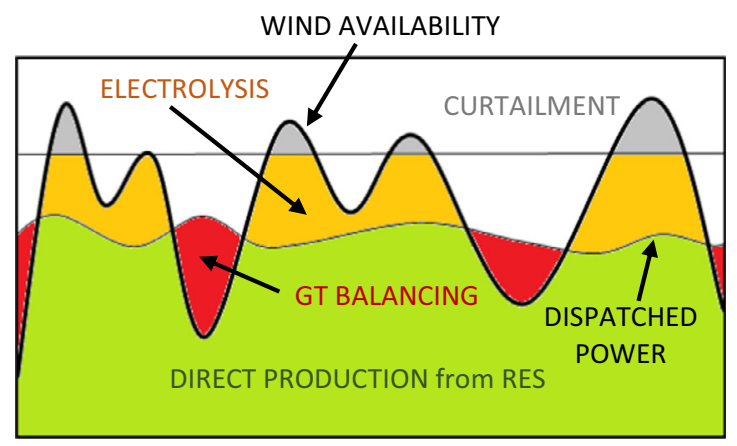

Fig. 1. General principle of integrating a fluctuating power source with an electrolysis system.
The general principle of operating an electrolysis system, as well as a gas turbine system, coupled with a fluctuating power source like a wind park, is presented in Fig. 1.

As shown in Fig. 1, this technology allows reducing wind curtailments and conceptually oversizing the installed renewable power with respect to the grid capacity, thanks to the possibility to absorb the unpredicted excess of production. Considering the point of view of a transmission system operator, power to gas systems can also contribute to mitigate the issues arising from the different timing between new production installation and grid infrastructure development. In addition, another positive effect of the power to gas technologies is the improvement of the renewable fraction of gaseous fuels ('greening' the natural gas) and the associated decrease of $\mathrm{CO}_{2}$ emissions from NG end uses.

This solution is quite different from the alternative storage system based on local storage of hydrogen and reconversion to electricity 'on demand' (e.g. by means of fuel cells). In both cases, if we consider the process from the point of view of electric energy storage, the global efficiency of the system suffers the intrinsic losses in the intermediate processes of the energy conversion chain (electricity to hydrogen and back to electricity). In addition to this, here hydrogen would substitute a fraction of natural gas not only used for power production but also burned for simple heating purposes, as well as potentially used in propulsion of compressed natural gas vehicles. In all uses, gas substitution would contribute to the reduction of $\mathrm{CO}_{2}$ emissions and may have a positive impact on the emissions of combustion appliances. The solution is also different from the case of hydrogen production and storage for fuel distribution, e.g. providing hydrogen to fleets of hydrogen vehicles [20], since it does not require a dedicated distribution infrastructure but it exploits the existing natural gas grid. Another considerable difference is related to the storage invest-ment cost: for P2G, the gas infrastructure represents the storage facility, so that the development of new large capacity storage sys-tems (e.g. underground caverns, large pressurized vessels, metal hydrates or others) is not required. The possible requirement of a local tank can be limited to the size of a short-time buffer. On the other hand, a lower overall system efficiency is obtained in case of thermal uses of hydrogen (e.g. combustion for simple heat generation), since this corresponds to a process where a high qual-ity form of energy (electricity) is eventually turned into heat with a rather low efficiency due to the losses in the electrolysis and hydrogen transport [32]. The electrolysis system also produces high purity oxygen, which could be stored and, in case of direct conversion back to electricity, used as oxidant in the fuel cells, increasing their performances. Alternatively, in case of $\mathrm{H}_{2}$ injection in the natural gas grid, oxygen could be used by industrial customers in the surroundings of the plant. This option is however not considered here due to the strong dependence on economics and customers availability, therefore considering to simply vent oxygen to the atmosphere when other purposes are not economical.

One of the main technical barriers to be faced, apart from economic ones, is the lack of detailed knowledge of the effects of the presence of hydrogen in the natural gas both for the final user and for the infrastructure itself. However, the results of a study lead by GERG (European Gas Research Group) show that an addi-tion of hydrogen up to about $10 \%$ in volume is in general possible in the natural gas infrastructure [35], confirming a previous estimation given by the European Project NaturalHY [36] where up to $20 \mathrm{vol} \%$ have been explored without negative issues for domestic appliances. Under such scenario, the storage capability shown in Table 1 would increase by one order of magnitude. However, still some important areas have to be investigated in this field, in particular: 
- Since hydrogen would be mixed with NG also within seasonal underground storages, one issue is the influence on porous rock environments, in which hydrogen could promote the growth of bacteria leading to the formation of $\mathrm{H}_{2} \mathrm{~S}$ and could damage the rock structure itself [37].

- Industrial gas turbines and gas engines can be strongly affected by changes in combustion properties; nevertheless, most of the issues could be solved with an accurate tuning of the system, at least for low hydrogen fractions. As an example, Ansaldo Energia has successfully reported mixing hydrogen in NG up to 12 vol\% in large combined cycles with modern F-class gas turbines (18,000 EOH cumulated on 2 units), without changes in the standard pre-mixed combustors [38]. Moreover, other experiences have demonstrated robust operation and achievement of NOx limits with modern combustors at engine operating conditions [39] with up to 15 vol\% hydrogen mixing.

- Issues may arise for the correct quality tracking of the H2 + NG mix delivered to the customers connected along the pipeline network, requiring a refinement in the grid modeling and management tools [40].

- Many gas chromatographic devices used for NG quality monitoring would not be able to detect hydrogen, mainly due to the fact that they typically use a carrier gas (helium) not adequate for this scope, and the same issue would appear in some methane detectors used as safety devices. In both cases, systems would need to be adapted in order to detect hydrogen/ methane mixtures.

Common criticisms about hydrogen use are related to its higher

adiabatic flame temperature, lower volumetric heating value and higher flame speed. These aspects are considered in the analysis reported in [35], where a set of combustion parameters relevant for fuel comparison is analyzed, namely Wobbe index, laminar flame speed, methane number. In the work it is reported that varia-tions resulting from 10 vol\% hydrogen dilution are usually within the acceptable range already occurring when burning natural gases with different compositions. However, hydrogen addition to natural gases with threshold compositions, i.e. already close to the extremes of the currently acceptable quality, could cause problems. A quantitative analysis of the effects of hydrogen admixture in natural gas on flames properties is reported in [41]. Unstretched flame propagation speed, laminar burning velocity and flame temperature are increased by the presence of hydrogen. Anyway, with up to $20 \mathrm{vol} \%$ of $\mathrm{H}_{2}$, deviations from pure methane combustion are limited. Laminar flame speed tends to increase by about $5 \%$ at 10 vol\% hydrogen, while a stronger effect (about $10 \%$ increase) is observed on turbulent flames speed [42]. The difference increases by an order of magnitude for hydrogen concentrations over $60 \mathrm{vol} \%$, which however is well beyond the scope of the P2G sys-tems, progressively requiring significant modifications to plants, appliances and engines, including gas turbines [43].

To summarize, on one hand it is not possible to specify a universal threshold for the admissible hydrogen content in natural gas, since such limits are very case-specific. However, from the practical point of view, few percentage points (i.e. up to 5 vol\%) are generally considered safe and should not cause malfunctioning of all the devices which are finally using the NG [35].

\section{Plant analysis}

The goal of this work is to assess the techno-economic performances of balancing systems based on the power-to-gas concept, coupled with traditional gas turbines. A quantitative analysis is set up in order to estimate the benefits achievable with these technologies and to assess the effects of different economic scenarios.
The optimal ratio between electrolysis and gas turbines installed power is determined by means of an economic evaluation of the balancing system. We consider state-of-the-art, fully industrialized heavy-duty or aero-derivative gas turbines, able to follow fast load variations. Electrolysis systems are low temperature, fast response, modular units; the solution adopted in order to give value to the $\mathrm{H}_{2}$ production is direct injection in NG pipelines, not considering here the option of methanation or synthetic methane production $[44,45]$.

The analysis is focused on wind power plants, due to their high power concentration, associated with a significant uncertainty in wind speed and energy production prediction. A complete list of the technical issues related to the management of wind power plants and their integration into the electrical network can be found in [9]. Among them, we focus on load following and unit commitment, since the aim of the technologies considered in this work is to improve the matching between the declared and the real power injection on an hourly basis. Nowadays in most of the EU countries, unforeseen power injection from renewable sources is generally allowed, but the situation is likely to change rapidly in the future, since the substantial increase of the amount of fluctuating power generated by renewables will make more and more difficult to manage the stability of the electric grid.

Aiming to setup a generalized approach, we consider here the case of the whole electricity production system of a typical European country, neglecting the real size and localization of each single power plant. This "lumped volume" approach is reasonable assuming - at least as a long term hypothesis and consistently with most grid system operators' evolution programs - that the transmission system is sufficiently powerful and robust to sustain all the required energy fluxes, without limitations due to line capacities.

For the purpose of calculation, we assume the case of a country (or a large geographical region) with a global installed wind capacity of $16 \mathrm{GW}$ (later referred to as 'wind park' or 'wind power plant network'), which also reflects the long-term prevision of installed capacity reported by the EU project SUSPLAN [46] for Italy, (see also the potential for wind power installations reported by ANEV [47]). Conclusions are however easily scalable to different overall power values.

\subsection{Statistical approach for wind energy production}

In order to provide a quantitative estimation of the effects of the balancing systems, it is necessary to evaluate the energy production on hourly basis from the whole wind generation capacity. Since this work considers a country-scale renewable power system, a possible reference is given by the work of Holttinen [48], who analyzed a large amount of data on energy production from different and widespread wind farms located in the EU Northern countries.

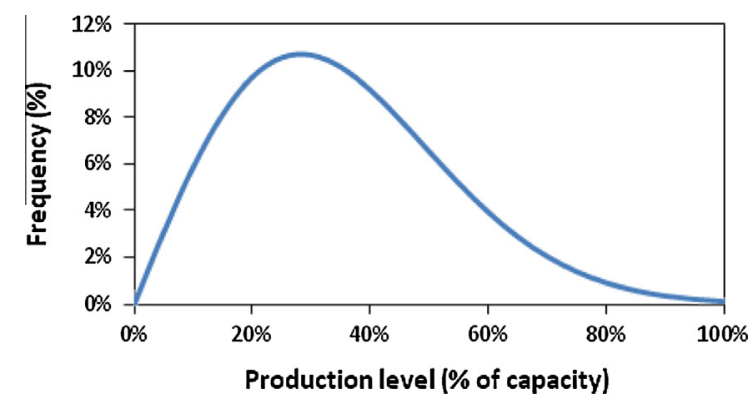

Fig. 2. Frequency distribution of geographically dispersed wind power production [48]. 
Among the different statistical analysis, a frequency distribution for production level (i.e. \% of installed capacity) is presented in Fig. 2. The curve expresses seasonal average production frequencies for the overall EU Northern countries area [48]. It is different from the conventional Weibull frequency distribution usually adopted in wind energy evaluations, due to effects of the season and of the country-wide geographic extension of the farms. For instance a complete absence of production or a saturation of the installed capacity are not observed, unlike for similar curves of single wind farms, where local conditions of zero wind or maximum (and above maximum) wind speeds are possible. This curve is used to define the frequency of a predicted value $\widehat{P}$ of electric energy production.

The short-term forecasting of wind power is still a recent tool characterized by large uncertainties. As a consequence, large deviations both in the speed and in the timing of the winds can occur.

A relative error of $20 \%$ on the energy production forecast is nowadays common, even if it can be reduced to much lower values by combining different forecasting models [49]. A normal Gaussian distribution for the relative error on the prediction of the producible power is assumed in this work, with average value $\mu=0$, as considered in literature [49]. This is reasonable under the assumption that provisional models will become sufficiently accurate to remove any systematic error, so that the phenomena become purely stochastic. Moreover, the influence of the bidding process on the deviation itself is not analyzed, due to the strong dependence on individual owner risk thresholds. Anyway, the fol-lowing discussion takes into account the influence of a storage sys-tem on the declared dispatch plan, so a pure forecasting deviation is assumed here. More refined functions could better fit actual forecast errors distribution, since for instance the Gaussian dis-tribution could underestimate the frequency of large errors. However a moderate impact of large errors can be anticipated on the final results, due to their low frequency.

The variance of this Gaussian distribution can be very site specific. In this work a variance $\sigma$ of about 0.08 is set to obtain a $\pm 20 \%$ range of possible prediction errors with probability $99.9 \%$ (Fig. 3), similar to the errors given in [49].

Given these assumptions, the probability that the real energy production is below a value $P$ can be calculated by Eq. (1):

$\mathcal{P}(P<\bar{P})=\int_{-\infty}^{\bar{\xi}} N_{\mu, \sigma}(\xi) d \xi$

where $N_{\mu, \sigma}$ is the normal probability density distribution function and $\xi$ is the relative forecast error, referred to a generic forecasted production $\widehat{P}$ (Eq. (2)).

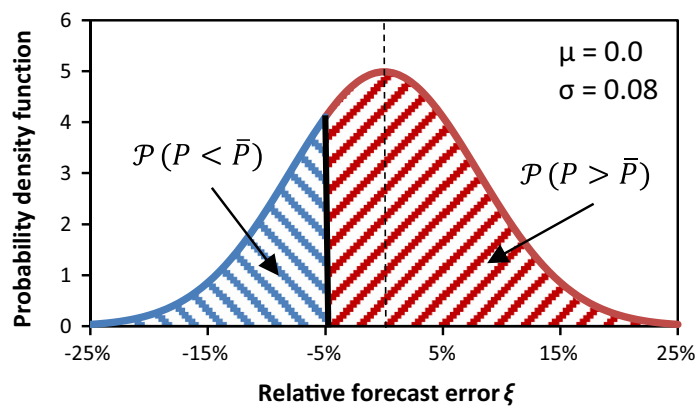

Fig. 3. Probability density function of the error of the forecasted wind power production. Areas under this function represent the probability that the actual power producible is below (blue) or over (red) a certain value $\xi$ (in figure equal to $5 \%$ less than the forecasted value). (For interpretation of the references to colour in this figure legend, the reader is referred to the web version of this article.)

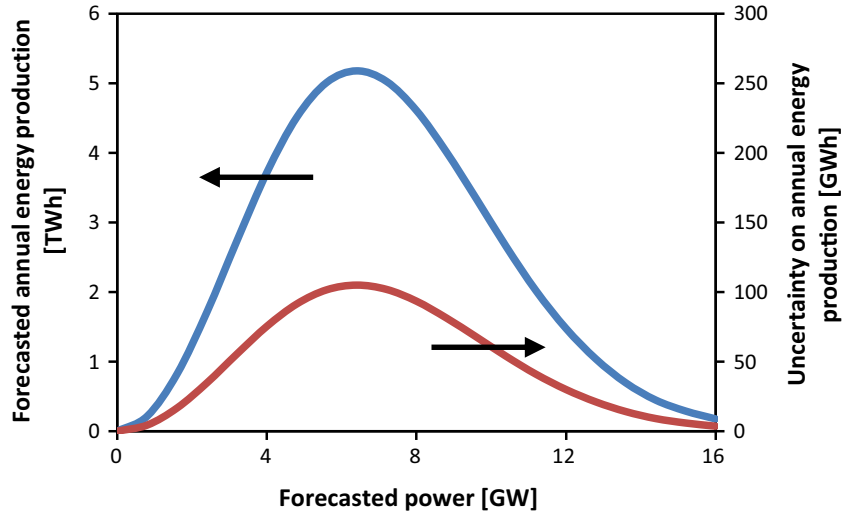

Fig. 4. Wind park annual energy production for each forecasted production level. Maximum deviation from forecasted production with a confidence $99.9 \%$ (total forecasted available energy for the $16 \mathrm{GW}$ wind park: $49.7 \mathrm{TW} \mathrm{h}$ ).

$\xi=\frac{\Delta P}{\widehat{P}}=\frac{P-\widehat{P}}{\widehat{P}}$

Combining the stochastic approach on forecast error with the production frequency distribution (Fig. 2), we obtain a range of wind power and energy generation as shown in Fig. 4.

\subsection{Economic assumptions}

The effects of the balancing system are compared with a baseline case where no balancing system is installed, accounting for each cost or revenue in differential terms with respect to such reference. Both the assumed technologies (EL and GT) aim to reduce the uncertainty on dispatched energy of a wind park, but they yield opposite effects on the electrical energy injected in the grid and on fuel flows (natural gas consumption and hydrogen production).

In the baseline case only the revenue of electricity sale and the cost of the unbalance (i.e. the declared production not effectively dispatched) are considered, while the available wind power exceeding the dispatchable power is considered to be lost.

The unbalance costs are particularly important in this analysis. They correspond to the costs that the transmission system operator (TSO) has to sustain in order to compensate a production of the wind farms lower than the declared one; the latter being given by the power plant operators (the producers) in a day-ahead mar-ket framework. We assume that this cost is charged to the produc-ers that do not fulfill their dispatch orders. Its value is chosen here as a multiple of the electricity market price. Therefore the unbal-ance costs represent an incentive to the producer to reduce the uncertainty of the available dispatched power. This situation could correspond to a mid-term evolution of the energy market, where new (or all) non-programmable renewables should no longer be granted priority dispatch with 'free-of-charge' fluctuations. Furthermore, the effects of a "carbon tax" and an incentive for "green gas" are included. The first one takes into account the costs associated to $\mathrm{CO}_{2}$ emissions, while the second one is a possible incentive to the production of fuels from renewable sources. This type of incentive is already considered for biogas in the EU, and a reasonable extension could be applied in the future to renewable hydrogen.

A summary of the considered economic parameters with their reference value is reported in Table 2 . In all cases the investment costs of the wind farms are neglected because they are neutral to the analysis, while both investment and O\&M costs of installed EL and GT systems are considered. 
Table 2

Assumptions on economic parameters: reference values and range of sensitivity analysis.

\begin{tabular}{llll}
\hline Parameter & & Ref. value & $\begin{array}{l}\text { Range of } \\
\text { sensitivity } \\
\text { analysis }\end{array}$ \\
\hline Equipment cost (EL) [52] & $€ / \mathrm{kW}$ & 400 & $100-2000$ \\
Equipment cost (GT AD) [50] & $€ / \mathrm{kW}$ & 270 & $200-300$ \\
Equipment cost (GT HD) [50] & $€ / \mathrm{kW}$ & 220 & $150-250$ \\
Electricity market price & $€ / \mathrm{MW} \mathrm{h}$ & 65 & $40-100$ \\
Natural gas market price & $€ / \mathrm{MW} \mathrm{h}$ & 25 & $20-45$ \\
Unbalance cost & $€ / \mathrm{MW} \mathrm{h}$ & 195 & $0-300$ \\
Carbon tax & $€ /$ ton $\mathrm{co2}$ & 15 & $0-60$ \\
"Green gas" incentives & $€ / \mathrm{MW}$ h & 0 & $0-20$ \\
Fixed O\&M costs (EL/GT HD) & $\mathrm{k} € / \mathrm{MW}$ year & 10 & \\
Variable O\&M costs (EL/GT HD) & $€ / \mathrm{MW}$ h year & 1.5 & \\
Fixed O\&M costs (GT AD) & $\mathrm{k} € /$ MW year & 15 & \\
Variable O\&M costs (GT AD) & $€ /$ MW h year & 2.25 & \\
\hline
\end{tabular}

The equipment costs are assumed equal to the overnight costs, without considering any scale effect, due to the modularity and the simplicity of installation of both these technologies. The total investment cost has been calculated as $80 \%$ higher than the equipment cost to take into account the installation, auxiliaries, indirect and owners costs [50]. Investment cost of the electrolysis system, that is a key input variable in this study, is chosen according to potential long-term market evolution. Nowadays, the electrolysis industry meets a small market demand, but as the demand for hydrogen increases, capital costs will reduce due to mass production. Current prices for complete alkaline systems can range from about 700 to $4000 € / \mathrm{kW}$ depending on the size of the device, while expected costs for PEM are even higher (up to $6000 € / \mathrm{kW}$ for large units) [27,51-54]. Anyway, the mid-term market development is expected to generate a reduction of the capital cost to about 400$500 € / \mathrm{kW}[20,27]$, while on long-term a reduction in the order of about 8 times is estimated $(100-200 € / \mathrm{kW})$ [52]. Values in the reference scenario and in the sensitivity analysis are chosen accordingly. The cost of the water treatment system, that is mandatory for electrolysis operation, is considered to be included in the auxiliaries investment costs. Moreover, it also influences the efficiency of the system and O\&M cost. Considering $2 \mathrm{~kW} \mathrm{~h} / \mathrm{m}^{3}$ water as energy consumption for the demineralization process, the decrease in global electrolysis efficiency is lower than $0.2 \%$. An O\&M cost of about $1 \mathrm{k} € / \mathrm{MW}$ year (about $1 € / \mathrm{m}_{\text {water }}^{3}$ ) is also included in the values reported in Table 2 .

Economic life is assumed 20 years for both cases. The annually based calculated cash flow $\mathrm{CF}_{\mathrm{t}}$ is actualized assuming a $7 \%$ interest rate and accounting for a $38 \%$ tax rate.

Three classic economic indexes are included in the analysis: the first two are the NPV (Net Present Value, sum of the actualized yearly cash flows along the useful life) and the PBT (Pay-Back
Time, that is the year in which the sum of actualized cash flows completely balances the initial investment cost). The third is the $I R R$ (Internal Rate of Return) which is the rate of return that makes the NPV zero (i.e. the discount rate for which the investment breaks even).

\subsection{Operational criteria}

As already introduced, a balancing system coupled with a variable renewable energy power source like a wind park aims at reducing the uncertainty of the declared dispatchable power of the whole power system. The operational criteria of such a balancing system determine the overall results in terms of energy and economic balances.

Fig. 5 presents an example ( $24 \mathrm{~h}$ ) of possible forecasted wind power production (dotted line). According to the statistical approach for prediction error, the bold line represents the plan of dispatchable power, assuming as an example an $80 \%$ probability of being able to produce the declared power. In other words, if such a dispatching plan is declared, averagely for $20 \%$ of the time the wind will not be enough to produce the declared power.

The $80 \%$ probability threshold could be in principle imposed to wind power producers by an external authority like the transmission system operator (TSO), in order to obtain a sufficiently statistically good prevision of the real power injected into the grid. However, an alternative regulatory approach is more frequently proposed (and considered in this work), consisting in setting an economic penalty related to the errors in electricity production declarations. In this way, each producer is motivated to improve the predictions and to optimize the costs and benefits related to the probability of a correct declaration. Assuming this scenario, targeting a high probability of correct dispatch causes a conservative power declaration: this on one hand generates a loss of revenue due to the high frequency of periods where the wind speed is higher than required to produce the declared power and the corresponding potential increase of power production (yellow areas) is not exploited. On the other hand, it allows incurring into lower penalties associated to unbalance costs (red areas), thanks to the lower probability that the wind speed is lower than required to generate the declared power. Since the two effects are in competition, an economic optimum exists. We consider that in the reference case (wind park with no balancing systems) the power producer selects the declaration of dispatched energy according to this optimum.

When introducing a balancing system, it is possible to attain better management of the wind park. An example of operational criteria on an hour-by-hour approach can be observed in Fig. 5. When an electrolysis system (labeled here EL) is introduced, a fraction of excess wind can be used to produce hydrogen by

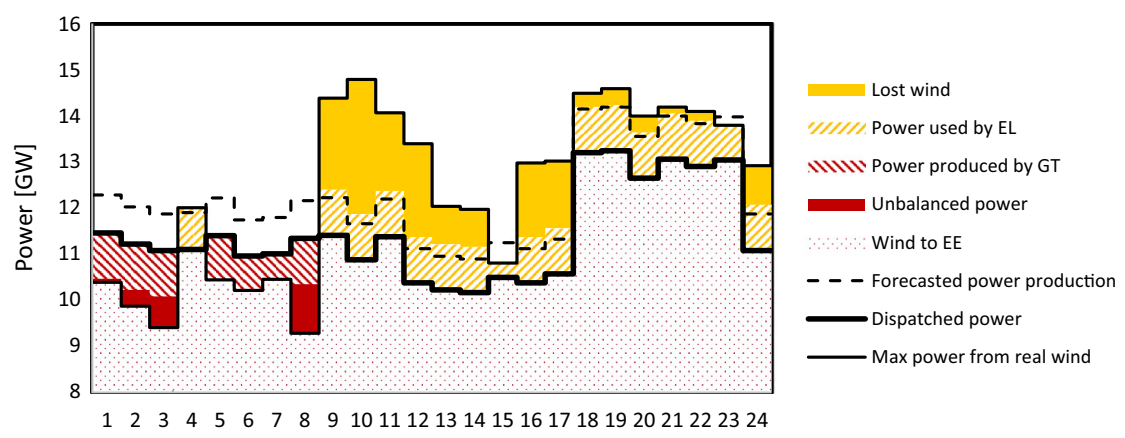

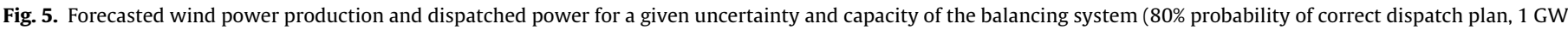
GT and 1 GW EL systems) 
electrolysis. This fuel can be sold to the natural gas grid and represents additional revenue. The quantity of energy recovered by the electrolyzers is shown in the example of Fig. 5 by the inclined yellow bars. It must be highlighted that the installation of an electrolysis system by itself allows reducing the lost wind, but the dispatchable power - with the given probability - does not change with respect to the reference scenario.

Introducing instead a gas turbine system (alone, labeled GT), it is possible to reduce the unbalance cost fees in hours with wind scarcity. Therefore, given a probability of correct declarations, the producer will declare to dispatch a higher power than the reference scenario with the same probability. The gain in dispatched power between this case and the reference one corresponds to the size of the installed gas turbine park. In other words, the same dispatching probability will be achieved by dispatching a power $P_{\text {disp-Nobal }}$ when no balancing system is present or a power $P_{\text {disp-Nobal }}+P_{G T}$ when a balancing gas turbine park of nominal power $P_{G T}$ is installed.

In both cases, we consider that the excess of wind energy either the total with respect to declaration or the fraction that cannot be managed by the balancing system - is curtailed and therefore lost.

The graphical comparison of Fig. 5 is carried out in order to clarify the matter with a balancing system having the same installed capacity of GT and EL (1 GW). Of course, the size of the system should be optimized on an economic basis, together with the probability of declaring a correct dispatch plan for different significant scenarios, as discussed in Section 4.

As far as the size of the balancing system is concerned, it can be anticipated that a large installed power will reduce the amount of lost wind (EL) and the penalty due to mismatch from the declared plan (GT). The benefits have to be weighted against the corresponding capital and operating costs, so that an optimal size will exist, again dependent on the economic scenario.

For a given dispatch probability, it is interesting to highlight that both technologies operate on a dispatch schedule allowing to reduce the wind energy lost:

(i) the EL by recovering part of the wind exceeding the level of dispatched power through $\mathrm{H}_{2}$ production;

(ii) the GT allowing to declare a higher or more 'aggressive' dispatched power profile, where the statistically wider regions of low wind (wind lower than expected) are partially covered producing extra power to keep up the dispatched energy schedule.

The results have nevertheless opposite implications in terms of primary energy balances and emission, as we will quantitatively show in Section 4: the EL generates a green fuel output (hydrogen), while the GT consumes a fossil fuel (natural gas) and yields additional emissions.

\subsection{Management of the gas turbine park}

In order to correctly evaluate the fuel consumptions of the gas turbine system, the performance of the whole gas turbine park considering the efficiency decrease of each turbine at part load has to be taken into account. Therefore, a dependence of the average efficiency on the nominal efficiency of the single machine, on its part load efficiency, on the number of gas turbines in the park and on the part-load control strategy has been considered.

As far as the single machine is concerned, two gas turbine classes have been considered, namely heavy duty (HD) or aeroderivative (AD), with nominal electric efficiencies of $35 \%$ and $40 \%$ respectively, intended representative of medium size

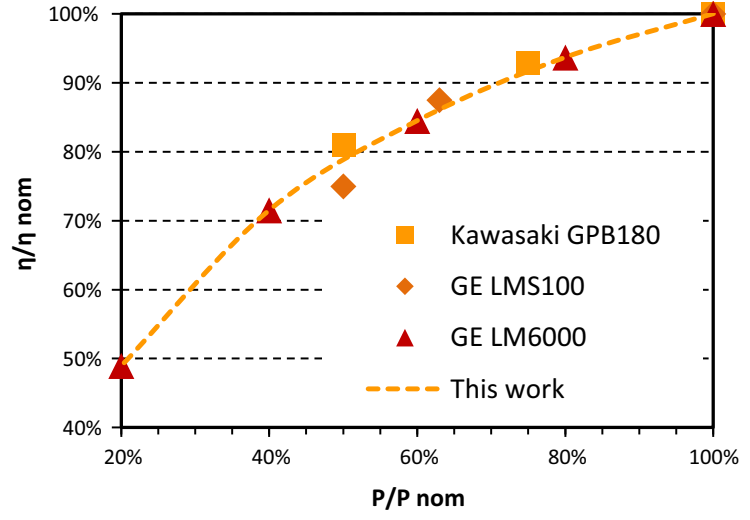

Fig. 6. Efficiency decrease of three commercial gas turbines [56-58] and regressed decrease curve used in this work

(40 MW and $35 \mathrm{MW}$ respectively) state-of-the-art turbines[50,55]. The efficiency decrease at part load has been defined by regressing the part load efficiency curves of three commercial turbines (two General Electric AD and a Kawasaki HD), which are characterized by sufficiently similar trends as shown in Fig. 6 .

The resulting correlation for the efficiency decrease is:

$$
\begin{aligned}
\eta / \eta_{\text {nom }}= & 0.7035 \cdot\left(P / P_{\text {nom }}\right)^{3}-1.91151 \cdot\left(P / P_{\text {nom }}\right)^{2} \\
& +2.0642 \cdot\left(P / P_{\text {nom }}\right)+0.1481
\end{aligned}
$$

When considering a gas turbine park formed by a number of machines, the average efficiency of the park at part load depends on the control strategy of the whole park, i.e. on the number of machines that are in operation and on their load. In general, for a given total power output, the preferable option is keeping in operation the lowest number of machines capable of producing the required power. In this way, the gas turbines would operate at the highest average load (hence at high efficiency) and the number of firing hours of each machine would be minimized (reducing in this way the O\&M costs) $[59,60]$. We assume here a control strategy where all the turbines under operation are managed in parallel at the same part load, yielding an overall partial load curve with the "saw tooth" shape lines shown in Fig. 7 for an example of two cases with a number of gas turbines $N_{\mathrm{GT}}$ equal to 7 or 23 .

According to this control strategy, starting from a $100 \%$ load condition where all the GTs operate at nominal power, if the total load decreases all the machines reduce their load in the same way and the resulting total efficiency decreases following the trend in Fig. 7, until one machine can be switched off (point A in figure,

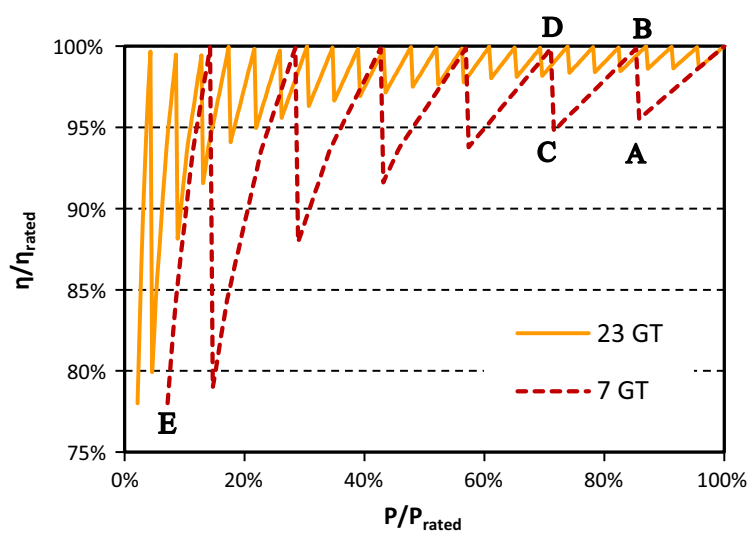

Fig. 7. Average gas turbine park efficiency at part load for different number of gas turbines in the park. 
for the case with $7 \mathrm{GTs}$ ). Then, all the other $N_{\mathrm{GT}}-1$ machines can be operated at the nominal load again, so that the nominal efficiency is re-established (point $B$ ). By reducing the total load further, the machines under operation are regulated at part load and the average efficiency reduces until the second gas turbine can be switched off (point C) and the remaining system of $N_{\mathrm{GT}}-2$ machines operate again at full load at the nominal efficiency (point $\mathrm{D}$ ). The control strategy proceeds in this way until one singe machine is maintained switched on and can be operated down to its minimum technical load (point E) [61].

In all cases, GTs are never operated below a minimum power, assumed here at 50\%, which ensures respecting environmental limitations on NOx and CO emissions. Despite latest generation gas turbines can reach turndown ratios of $30 \%$ or $25 \%$ of the nomi-nal load without exceeding emissions limits $[62,63]$, in this work we keep current technical limitations to avoid the influence of modelspecific assumptions. At any rate, reduction of the mini-mum GT load would very marginally affect the results of this work, as it can be demonstrated by a specific sensitivity analysis, not reported here for brevity.

Other strategies have been tested, keeping the target of minimizing the number of machines under operation. For example, a given power can be obtained at constant $N_{\mathrm{GT}}$ by keeping some machines at maximum load and operating the others at a partial load; however, it has been verified that the differences on the average efficiency of the GT park are negligible. On the contrary, the preliminary choice of $N_{\mathrm{GT}}$ for a given total nominal power (i.e. the size of each machine) can have a significant effect on part load efficiency. This effect is evident in Fig. 7 comparing the cases with 7 and 23 turbines. Thanks to the lower contribution of each machine to the total power, a case with higher $N_{\mathrm{GT}}$ allows to stop each turbine earlier when reducing the total power; hence the nominal efficiency can be re-established earlier, yielding a higher average park efficiency.

Other variables that strongly affect gas turbine performance are the ambient temperature and pressure. However, ambient conditions are very site-specific and variable with the season and the hour of the day, so that considering accurately these effects would add substantial complexity to the mathematical problem, because of the requirement of a statistically grounded relation among temperature, wind power production and forecasting error that is also very site-specific. This level of detail is not compatible with the general stochastic optimization approach chosen here and with the available data. Therefore, the effects of ambient conditions have been neglected in this work.

In order to calculate the fuel consumed by the GT park for a given predicted wind condition, the efficiency curve of the park has to be weighted with the probability density function of the forecasted wind error. To explain the procedure used, we refer to Fig. 8. In each point of the curve of wind power production distribution (e.g. at $40 \%$ of total capacity in Fig. 8a), a probability density function of the forecasted wind power error exists (Fig. 8b). On this graph, the GT park will operate between the minimum load condition and its maximum power. The location of the point of minimum power $P_{\min }$ will depend on the considered dispatch probability (for instance $90 \%$ in Fig. 8 b), while power generated at its the maximum power is obtained by summing to $P_{\min }$ the GT park power range (i.e. the maximum power minus the mini-mum load power) and corresponds to the dispatched power $P_{\text {disp. }}$. When the electrolysis system is also present, its power range is added to the dispatched power, contributing in this way in the cases when wind power exceeds the dispatched one up to the maximum value $P_{E L}$.

Therefore, the fuel consumption $\mathrm{F}$ (and then the average GT park efficiency) at each forecasted wind condition $\widehat{P}$ will result (c)

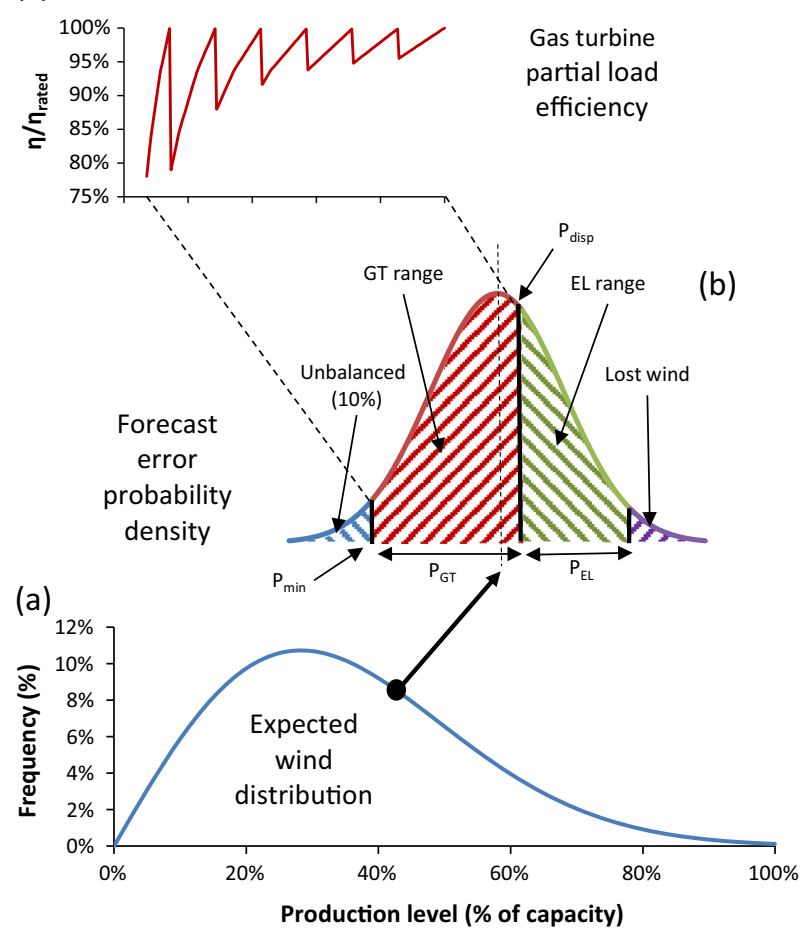

Fig. 8. Logical pathway adopted to calculate GT performances. For each point of the wind park production probability curve (a), the normal probability density function (b) described before is applied. The fuel consumption is therefore calculated from the electrical power requirement and the GT efficiency curve (c) weighted on the probability of each load condition.

from integrating the average park fuel consumption $P_{\mathrm{GT}} / \eta\left(P_{\mathrm{GT}}\right)$ (where $\eta\left(P_{\mathrm{GT}}\right)$ is the curve in Fig. $8 \mathrm{c}$ ), weighted with the error frequency function $F_{\text {err }}(P, \widehat{P})$ (Fig. $8 \mathrm{~b}$ and c) in the appropriate $P_{\min }-P_{\text {disp }}$ power range (or the equivalent non-dimensional $\xi_{\min }-\xi_{\text {disp }}$ range), according to Eq. (4)):

$F(\widehat{P})=\int_{\xi_{\text {min }}}^{\xi_{\text {disp }}} F_{\text {err }}(\xi) \frac{P_{G T}(\xi)}{\eta\left[P_{G T}(\xi)\right]} d \xi$

where $\xi$ is the relative deviation of wind park production P from forecasted value $\widehat{P}$, as defined in Eq. (2), and the function $F_{\text {err }}(\xi)$ is the normal probability density function adopted in order to model the relative forecasting error as described in Section 3.1. The gas turbine park efficiency is calculated as described before. The overall power of the gas turbine park $P_{G T}(\xi)$ is calculated from the production of the wind park as:

$P_{G T}(\xi)=\widehat{P}\left(\xi_{\text {disp }}-\xi\right)$

With respect to the electrolysis system, such a complex approach to describe the part load behavior is not justified. As a matter of fact, electrolysis systems are strongly modular (largest stacks for atmospheric devices are in the order of few $\mathrm{MW}_{\mathrm{el}}$ ) and different sections of the system can be managed independently in order to minimize efficiency losses. Moreover, the electrochemical cells slightly increase their efficiency at part load, whereas the effect of the consumption of auxiliaries increases. At very low loads, the negative effect of auxiliary consumption prevails over the benefits of the more efficient electrolysis process. A common lower limit for the operation range is $20 \%$ of nominal power, due to safety issues to avoid internal mixing of hydrogen and oxygen by permeation. Therefore, a constant efficiency of $60 \%_{\mathrm{LHV}}$ is assumed for the electrolyzers in the operation range [64]. It is 
worth mentioning that recent results from the operation of demonstration plants [65] suggest that this assumption is conservative, but consistent with state-of-the-art technology.

Stochastic optimization methodology described cannot catch dynamics of the system, because of the lack of a direct dependence on time; therefore, a detailed analysis is mandatory in case of frequency control applications (primary regulation). This work is focused on energy production balancing on a medium time scale (secondary and tertiary regulation services) and on long term energy storage.

\subsection{Avoided $\mathrm{CO}_{2}$ emissions}

A remarkable difference between EL- and GT-based system is the effect on the global emissions. In particular, we consider the $\mathrm{CO}_{2}$ released in order to evaluate this aspect.

For the economic evaluation, emissions are calculated in differential terms (i.e. emissions avoided), referring to a baseline case in which no balancing system is adopted. On one hand, the additional $\mathrm{CO}_{2}$ emission resulting from the combustion in the GT is evaluated from the fuel consumption (see Section 3.4), assuming an emission factor of $202 \mathrm{~kg} / \mathrm{MW} \mathrm{h} \mathrm{h}_{\text {fuel }}$. On the other hand, the $\mathrm{H}_{2}$ produced and injected in the natural gas grid would substitute a fraction of the final energy consumption, proportionally avoiding emissions.

Furthermore, contribution associated to the differential electric power injected in the grid (from both wind power and GT balancing system) must be accounted for. In general, such contributions can result from both the higher dispatched power and from the lower production of the reserve plants, allowed by the presence of the balancing system. Therefore, the definition of an average emission factor of the power plants participating to the ancillary services market is needed. In this work, we assume as reference power generation park composed by natural gas fuelled combined cycles with an average net efficiency of $55 \%$, resulting in specific emissions of $367 \mathrm{~kg} / \mathrm{MW} \mathrm{h} \mathrm{h}_{\mathrm{el}}$. In some conditions, a reduction of the dispatched renewable energy could be economic in order to avoid unbalances; as a consequence, the lower dispatched power causes an increase of production by other plants (i.e. the traditional ones), reducing the benefits from the point of view of $\mathrm{CO}_{2}$ emissions.

\section{Plant comparison and annual balances}

The methodology described above is applied to a $16 \mathrm{GW}$ wind power park behaving as discusses inSection 3. The results of this analysis are closely related to the assumptions about the quality of the forecast (i.e. the variance of the probability distribution density function of the relative forecast error described in paragraph 2.1). A reduction in the uncertainty leads to fewer transmission grid issues and, consequently, to smaller balancing systems. Nevertheless, the influence on the optimal dispatch probability is very small. Anyway, the consequent lower investment in balancing systems must be compared with an expected increase in the costs for the forecasting system.

First of all, the NPV is calculated as function of the installed capacity in the reference scenario (see Table 2). For each couple of EL and GT installed capacity, the optimum probability of declaring a correct dispatch plan is calculated. A heuristic approach is applied in order to get the complete maps of the economic return, probability of correct dispatch plan and other significant parameters. A worksheet performs the calculations, applying the probability distributions. Fig. 9 shows the results respectively for HD and AD gas turbine families. As it can be observed, the reference scenario is not favorable to power-to-gas systems, since the maximum revenue
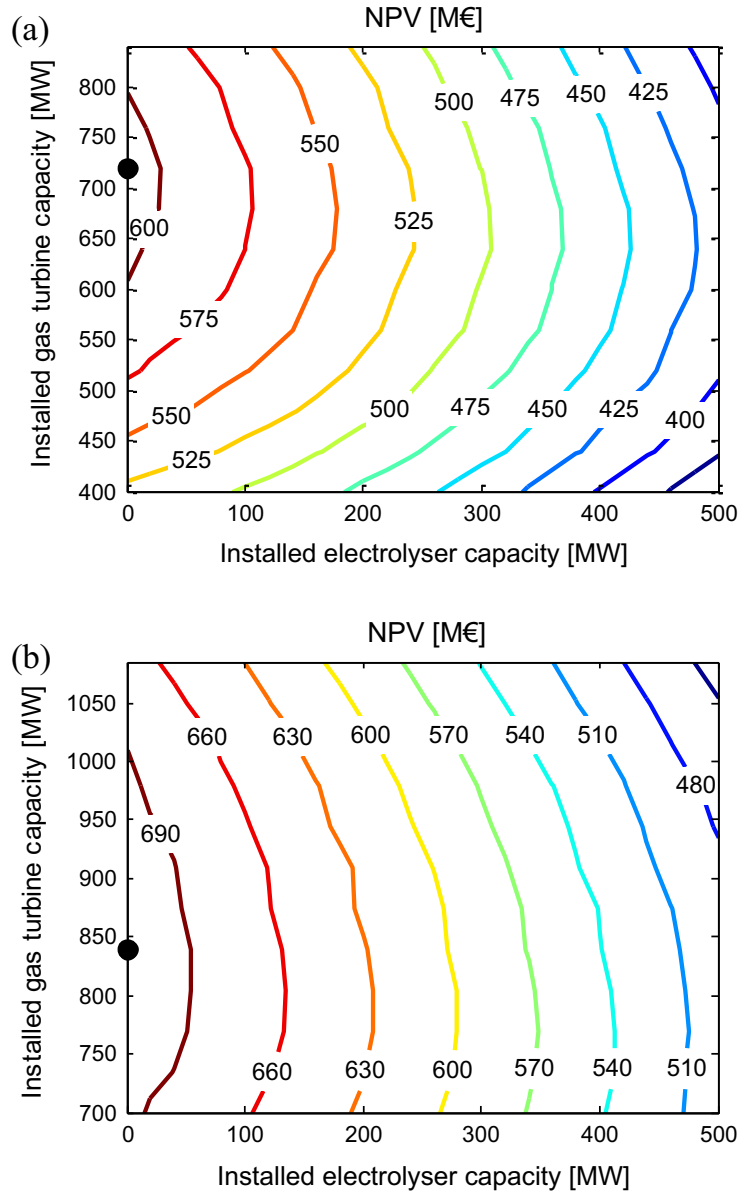

Fig. 9. NPV as function of the installed capacity of both EL and GT in the reference case. In each point, the optimal probability of correct dispatch plan is considered. Both HD GT (a) e AD GT (b) are considered.

Table 3

Parameters of different economic scenarios.

\begin{tabular}{llrrrrrr}
\hline & & Ref & A & B & C & D & E \\
\hline Investment cost $^{\mathrm{a}}[€ / \mathrm{kW}]$ & EL & 720 & 270 & 270 & 270 & 270 & 270 \\
& GT AD & 500 & 400 & 400 & 400 & 400 & 400 \\
& GT HD & 390 & 312 & 312 & 312 & 312 & 312 \\
Market price [€/MW h] & EE & 65 & 65 & 65 & 65 & 100 & 65 \\
& NG & 25 & 25 & 40 & 25 & 38 & 40 \\
Unbalance cost [€/MW h] & & 195 & 195 & 195 & 195 & 300 & 300 \\
Green gas Inc. [€/MW h] & & 0 & 0 & 0 & 20 & 0 & 20 \\
Carbon tax [ $€ /$ ton $_{\text {Co2 }}$ ] & & 15 & 15 & 15 & 40 & 15 & 60 \\
\hline
\end{tabular}

a Including $80 \%$ addition for installation and auxiliaries.

occurs when no electrolysis balancing system is installed. A GT capacity of about $4.4-5.3 \%$ of the wind park capacity is required to improve up to about $90 \%$ the probability of correct dispatch plan. Remarkable NPVs are obtained with both HD (Fig. 9a) and AD (Fig. 9b) technologies, this last featuring the highest revenue.

Nevertheless, the diminishing returns obtained by increasing the electrolysis capacity are not so large as to prevent the presence of power-to-gas systems in more favorable economic scenarios. To discuss this point, we evaluate the influence of the assumptions on the results considering different possible situations, according to the scenarios in Table 3.

In the first scenario, labeled $\mathrm{A}$, a strong reduction of the investment cost of the electrolysis system is assumed. Scenarios B, C, D and $\mathrm{E}$ consider further changes respectively due to (i) a reduction 
Table 4

Results for the cases without balancing systems.

\begin{tabular}{lll}
\hline & Ref/A-D & E \\
\hline Optimal probability of correct dispatch [\%] & 74.7 & 80.5 \\
Wind energy to the grid [TW h/year] & 46.45 & 45.75 \\
Lost wind [TW h/year] & 3.25 & 3.95 \\
Lost wind [\% total wind energy] & 6.53 & 7.93 \\
\hline
\end{tabular}

of the ratio between the prices of electricity and natural gas, (ii) the presence of incentives for green gas and an increase of the carbon tax, (iii) a global increase of prices on the energy market and (iv) an increase of the unbalance costs.

As stated before, the economics of the system are calculated relatively to a reference case in which the same dispatch policies and economic assumptions are applied, but in absence of a balancing system. For all the scenarios, the same reference unbalanced operations are obtained, with the exception of case E, because only the price of electricity and the unbalance cost affect the unbalanced case. If the ratio between these two values is the same, as in cases A-D, the optimal case in absence of balancing systems does not change. As a consequence, in the following just two different reference cases are shown as "no balancing". The results for these cases are shown in Table 4.

For each scenario, the optimum capacities of both GT and EL systems are obtained by maximizing the NPV (Fig. 10). The economic return depends also on the required probability of correct dispatch plan; therefore, this parameter is considered as a third optimization variable. A detailed report of results obtained with cases A-E is shown in Table 5 , which includes the main performances indexes.

First of all, we can observe that we can clearly distinguish two groups of scenarios: one favorable to power-to-gas systems, the other tending to the traditional technology. In particular, a higher ratio between natural gas and electricity market prices (case $B$ ), the presence of a "green gas" incentives scheme (case C) and high unbalances costs coupled with a favorable gas market (case E) would lead to best results adopting a "power-to-gas" based balancing system.

Moreover, "lost wind" is economically less significant than the unbalance cost; consequently, in an EL based balancing system the optimal solutions include the installation of a remarkable amount of GT power.

Fig. 11 shows the probability of declaring a correct energy dispatch plan that maximizes the economic return (NPV). In

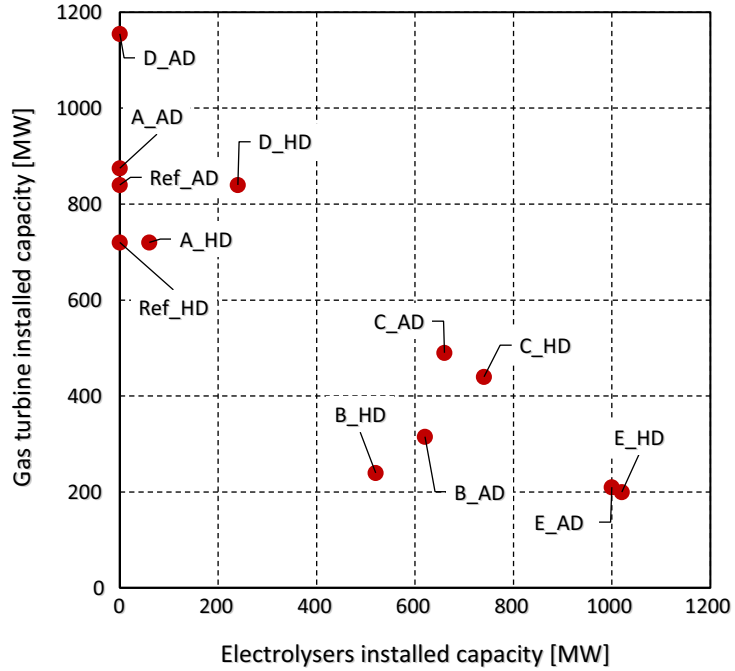

Fig. 10. Optimal balancing system for each scenario, considering the optimum probability of a correct dispatch (see Table 5).

comparison with the case with no balancing system (labeled 'No_bal' in figure), all the proposed solutions could lead to a remarkable reduction in the uncertainty of the energy flows injected into the grid - i.e. gain of probability of correct dispatch plan declaration - that is ultimately the goal of the TSO. Anyway, the effects on the total energy recovered from wind are different, depending on the prevalence of electrolysis or gas turbines. In general, reduction in curtailments is more effective in presence of electrolysis systems (cases B, C, E); but if we include also the internal losses of the electrolyzers, the amount of total lost wind energy is larger.

The probability of correct dispatch plan influences strongly the economic return, as shown in Fig. 12. Nevertheless, the NPV trend is rather flat around the maximum.

Several general conclusions can be drawn from the results obtained in this analysis:

- The choice of an AD gas turbine rather than a HD one has a moderate influence on the optimal size of the system. Generally speaking the $\mathrm{AD}+\mathrm{EL}$ solution finds a better optimum in terms of NPV but lower IRR and longer return on investment, although the differences are not large. In terms of optimized power, the

Table 5

Parameters and results for the different scenarios.

\begin{tabular}{|c|c|c|c|c|c|c|c|c|c|c|c|c|}
\hline & \multicolumn{2}{|l|}{ Ref } & \multicolumn{2}{|l|}{ A } & \multicolumn{2}{|l|}{ B } & \multicolumn{2}{|l|}{ C } & \multicolumn{2}{|l|}{$\mathrm{D}$} & \multicolumn{2}{|l|}{$\mathrm{E}$} \\
\hline & $\mathrm{EL}+\mathrm{AD}$ & $\mathrm{EL}+\mathrm{HD}$ & $\mathrm{EL}+\mathrm{AD}$ & $\mathrm{EL}+\mathrm{HD}$ & $E L+A D$ & $\mathrm{EL}+\mathrm{HD}$ & $\mathrm{EL}+\mathrm{AD}$ & $\mathrm{EL}+\mathrm{HD}$ & $\mathrm{EL}+\mathrm{AD}$ & $\mathrm{EL}+\mathrm{HD}$ & $\mathrm{EL}+\mathrm{AD}$ & $\mathrm{EL}+\mathrm{HD}$ \\
\hline $\begin{array}{l}\text { Optimal electrolysis installed power } \\
{[\text { [MW] }}\end{array}$ & 0 & 0 & 0 & 60 & 620 & 520 & 660 & 740 & 0 & 240 & 1000 & 1020 \\
\hline $\begin{array}{l}\text { Optimal gas turbine installed power } \\
{[\mathrm{MW}]}\end{array}$ & 840 & 720 & 875 & 720 & 315 & 240 & 490 & 440 & 1155 & 840 & 210 & 200 \\
\hline $\begin{array}{l}\text { Optimal probability of correct dispatch } \\
{[\%]}\end{array}$ & 90.5 & 90.7 & 91.1 & 90.3 & 87.6 & 86.8 & 89.8 & 90.2 & 93.0 & 92.2 & 93.0 & 92.2 \\
\hline Net Present Value $[\mathrm{M} €]$ & 710 & 609 & 773 & 651 & 392 & 355 & 655 & 603 & 1582 & 1274 & 941 & 857 \\
\hline Pay Back Time [years] & 5 & 4 & 4 & 4 & 6 & 5 & 5 & 5 & 3 & 3 & 4 & 4 \\
\hline IRR $[\%]$ & 26.1 & 30.8 & 31.2 & 36.0 & 22.5 & 25.7 & 26.7 & 27.1 & 42.9 & 47.4 & 35.5 & 34.4 \\
\hline Avoided $\mathrm{CO}_{2}$ emissions [kton/year] & -743.5 & -667.1 & -802.0 & -657.2 & 147.2 & 117.0 & 16.8 & -3.3 & -1463 & -840.3 & 36.5 & -1.1 \\
\hline Lost wind [TW h/year] & 1.25 & 1.58 & 1.22 & 1.38 & 0.84 & 1.14 & 0.64 & 0.62 & 0.84 & 0.90 & 0.76 & 0.69 \\
\hline Lost wind [\% total wind energy] & 2.51 & 3.18 & 2.46 & 2.78 & 1.70 & 2.30 & 1.29 & 1.25 & 1.70 & 1.82 & 1.53 & 1.39 \\
\hline EL equivalent hours [h/year] & - & - & - & 2769 & 3166 & 3773 & 2503 & 2619 & - & 2149 & 3631 & 3422 \\
\hline EL full load hours [h/year] & - & - & - & 2639 & 1727 & 2309 & 1302 & 1258 & - & 1739 & 1463 & 1350 \\
\hline GT equivalent hours [h/year] & 3823 & 3419 & 3833 & 3469 & 2352 & 2109 & 2729 & 2493 & 4296 & 3563 & 1322 & 1593 \\
\hline GT full load hours [h/year] & 831 & 817 & 775 & 846 & 1087 & 1159 & 891 & 861 & 611 & 683 & 611 & 683 \\
\hline Average GT efficiency [\%] & 39.64 & 34.59 & 39.65 & 34.59 & 39.33 & 34.31 & 39.45 & 34.41 & 39.72 & 34.63 & 38.98 & 33.81 \\
\hline
\end{tabular}




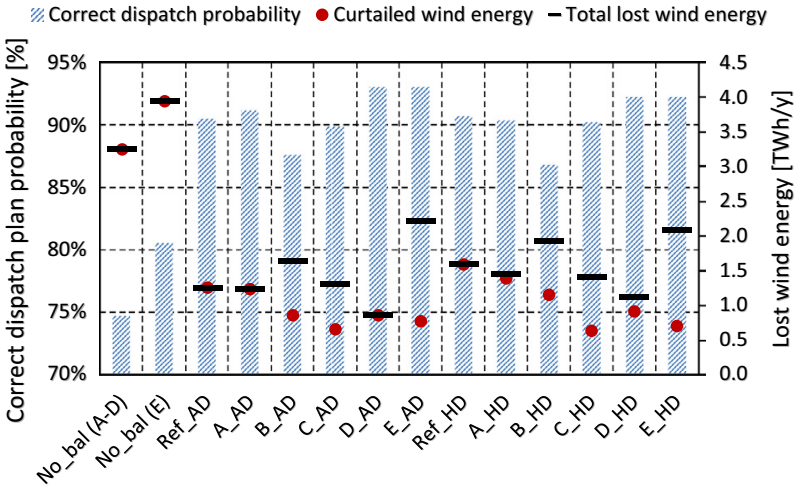

Fig. 11. Optimal probability of correct dispatch plan declaration in the best case for each scenario in Table 3, compared with the amount of lost wind energy due to curtailment and electrolysis efficiency.

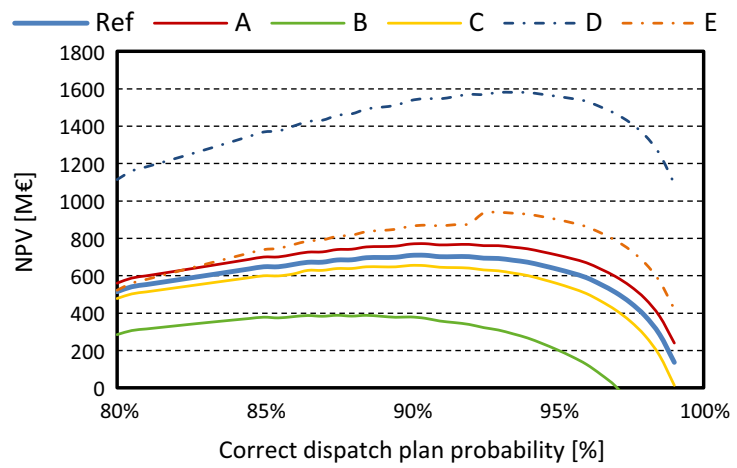

Fig. 12. NPV as function of probability of correct dispatch plan for AD GT cases (optimal size of both EL and GT).

AD + EL option relies on a slightly larger gas turbine park. The peak difference is in case $D$, where the high value of both electricity and fuel magnifies the effect of GT efficiency and the AD optimum GT power is 38\% larger than the HD GT one.

- The influence of the investment cost is important but not sufficient alone to make the EL system prevalent over the GT in terms of installed power (high NG costs and green gas incentives are needed for this condition to occur). In all the cases, the optimum involves the adoption of GTs, whose installed power never reduces to zero. In case $A(E L$ at $270 € / \mathrm{kW}$ ), that can represent a mid-term scenario, the best balancing system is still based on GT, with a small EL contribution only for the case with industrial gas turbines. Further EL cost decrease would change the situation in favor of hydrogen systems. Anyway, the presence of a small GT system could result economically attractive in order to sell electricity that has a higher economic value also during unforeseen wind scarcity periods.

- Case B considers the effect of a low ratio between the costs of electricity and natural gas, which reverses the situation of case A and brings the EL system to take most (about two thirds) of the installed balancing power. The reduction of the gap between electricity and gas prices could be a consequence of different possible technological and market scenarios, including for example a long-term increase of natural gas prices due to increasing demand of clean fuels (i.e. $\mathrm{NG}$ and $\mathrm{H}_{2}$ ). On the other hand, the introduction of more efficient gas fired conventional power plants, the reduction of the investment cost of renewable energy technologies, or a reduction of the coal price could contribute to avoid high variations of the electricity prices. In all cases, the remuneration due to hydrogen sale, the loss due to the reduction in dispatched electricity and the additional fuel cost for the gas turbine tend to promote the EL system. An equivalence between the two technologies in terms of optimum installed power can be reached at an electricity-to-fuel cost ratio of about 1.8 with a price of electricity of $65 € / M W h_{e l}$ (i.e. a NG price of $36 € / M W h$ in scenario A). This threshold becomes higher if the absolute prices are higher (i.e. around 2.0 at about $100 € / \mathrm{MW} \mathrm{h}_{\mathrm{el}}$ in scenario D).

- The introduction of a "green gas" subsidy and the increase of the "carbon tax" also lead to a substantial improvement of the economic convenience of the electrolysis system. Singularly taken, they do not assure the economic convenience of the 'green' EL technology, but if associated with a reduction of the specific investment costs they can strongly push the competitiveness of the electrolysis system. This situation is shown for case $\mathrm{C}$ : when both the green gas incentive and the carbon tax are introduced, the EL reaches an installed power of about $700 \mathrm{MW}$ with NPV comparable with the reference case.

- A primary role in the variation of the correct dispatching probability is played by the unbalance cost, which is the penalty for incorrect power dispatch declaration. At very high costs ( $300 € / \mathrm{MW} \mathrm{h}$ ) optimal dispatching probabilities are higher than $90 \%$, with high revenues. Case D shows this effect in a high-price energy market: the GT system contribution becomes very important in order to limit mismatches with the declared plan, while the effect of lost wind becomes less important. The best scenario for the EL technology is obtained when unbalance costs are associated with green gas incentives and high carbon tax (case E), in an energy market with prices similar to the current ones.

Fig. 13 shows the same type of diagram already used for the reference case (see Fig. 9), but drawn as an example for the scenario C, which shows a balanced amount of installed GT and EL power. It is possible to see that the iso-NPV curves mildly sensitive to the installed power, with a positive revenue for a large power range. These two aspects make the solution reliable despite the presence of uncertainties and arbitrary choices related to the economics of the system.

Finally, it is interesting to discuss the yearly energy balance of each optimized case, shown in Fig. 14. The sum of the shares, with the exception of the GT related ones, corresponds to the available wind energy (about $49 \mathrm{TW}$ h/year). In all the cases with a balancing system installed, the lost wind energy reduces. In most of the cases, the electricity from wind injected in the grid increases, as a result of the larger dispatched power made economically

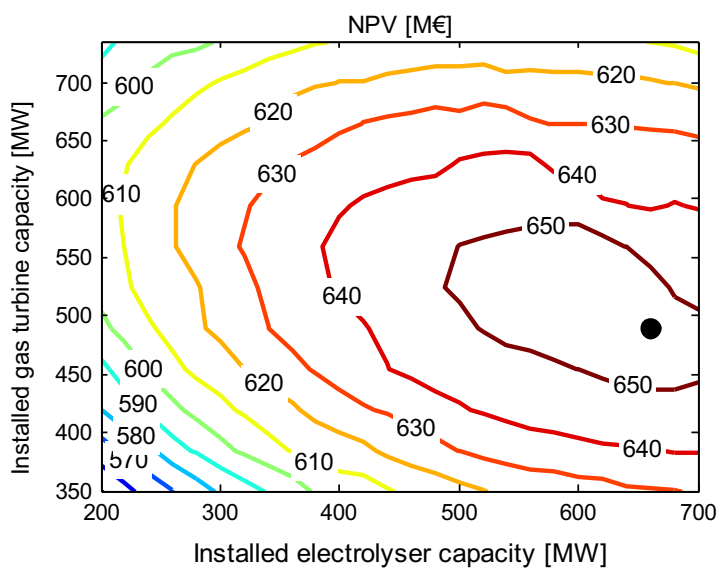

Fig. 13. NPV as function of the installed capacity of both EL and AD GT in case C. In each point, the optimal probability of correct dispatch plan is considered. 


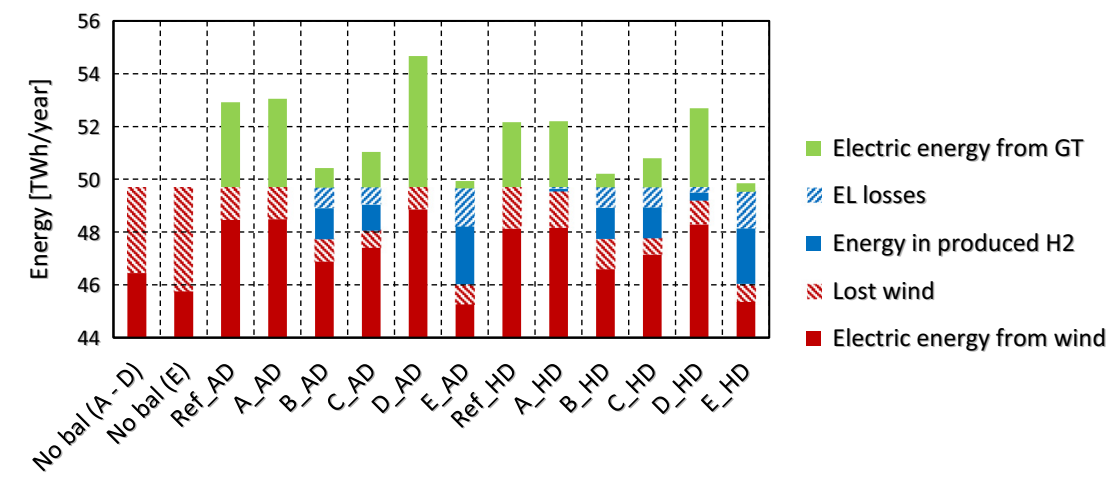

Fig. 14. Annual energy balance.

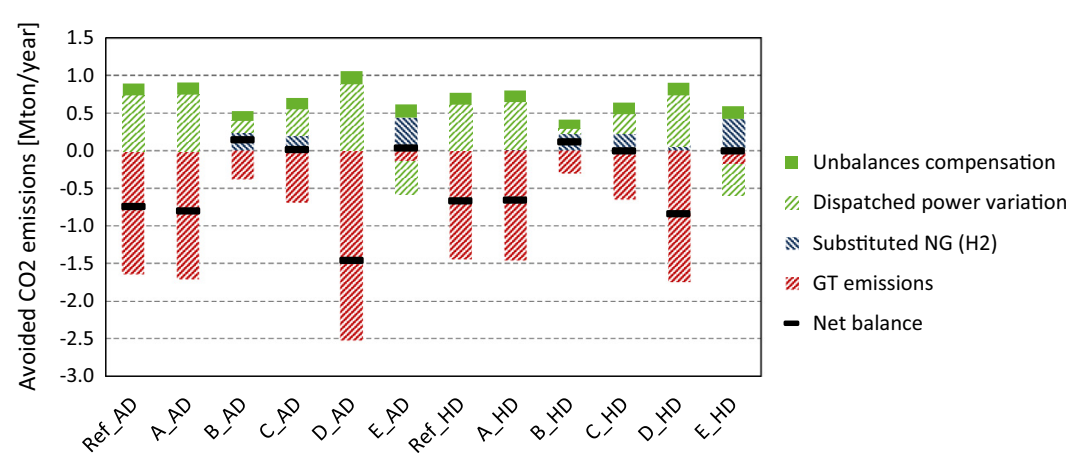

Fig. 15. Avoided $\mathrm{CO}_{2}$ emissions.

attractive by the presence of the gas turbine-based balancing system. In general, the larger the gas turbine park, the higher the wind electricity produced. Case D_AD is the one leading to the highest wind energy production (and to the highest gas turbine installed power). For this case, an energy production from the gas turbines of about $5 \mathrm{TW}$ h/year is obtained, corresponding to about $10 \%$ of the yearly production of wind electric energy. Only in the scenario E, where a high optimal capacity of the electrolysis system and a low optimal GT installed power result, the wind electric energy injected in the grid is lower than in the reference unbalanced case. Such an effect is the result of the higher optimal probability of correct dispatch, coupled with the lower dispatched power due to the large consumption of the electrolysis system with respect to the reference case. In addition, due to the losses associated to hydrogen production by the electrolyzers, the total wind energy lost (i.e. the sum of the actual wind energy lost and the losses due to the inefficiencies of the electrolyzers) is the highest among the cases which include a balancing system.

By comparing the systems from the point of view of the avoided $\mathrm{CO}_{2}$ emissions, only the cases predominantly based on the electrolysis balancing system (B, C and E scenarios) are substantially neutral or lead to some $\mathrm{CO}_{2}$ avoidance with respect to the unbalanced cases. This is because the avoided $\mathrm{CO}_{2}$ emission associated to the higher wind energy injected in the grid and the green gas production offset the emissions generated from the gas turbine park. In all the other cases, where the balancing system is dominated by gas turbines, increased overall $\mathrm{CO}_{2}$ emissions are obtained despite the higher wind energy production. This effect is the consequence of the higher average emission factor of the balancing gas turbine park with respect to the average electric park assumed for the tertiary reserve, which is based on more efficient combined cycles. By this point of view, any carbon-constrained scenario ( $C$ and $E$ ) has the tendency to be more favorable to the EL than to the GT solution, although relatively high carbon taxes
(60 $€ /$ ton $_{\mathrm{CO} 2}$ as in case $\mathrm{E}$ ), combined with other factors, are needed to make the effect visible in terms of optimized installed power. From the point of view of the avoided emissions, the best scenario is the case $\mathrm{B}$, where the significant reduction of $\mathrm{CO}_{2}$ is coupled with a high number of operating equivalent hours for the electrolysis system. The breakdown of the contributions to the avoided $\mathrm{CO}_{2}$ emissions is detailed in Fig. 15. The largest positive contribution is due to the increased wind energy injection in the grid that decreases the energy produced by traditional power plants. Additional emissions are mainly related to the GT system. An anomalous case is the scenario $\mathrm{E}$, that includes a large electrolysis system. In this case, a significant role is played by the "green" gas injected in the natural gas grid that substitutes carbon-based (methane) one in the final uses. Nevertheless, the net balance is again close to zero due to the reduction in the wind energy dispatched to the grid (see Fig. 14) that has to be produced by means of traditional plants. To be noticed that, in the next future, this contribution will tend to decrease due to the development of more efficient combined cycles with increased flexibility capabilities and the increased share of carbon-free technology in the electricity generation park.

\section{Conclusions}

After the evaluation of different economic scenarios, the statistic model described in this work allows drawing some general considerations about the adoption of a power-to-gas balancing system with hydrogen injection in the NG grid, when applied to large scale wind power plant systems representative of a country or a wide regional area. First of all, nowadays the 'business-as-usual' economic conditions related to both investment costs and energy markets are not favorable to power-to-gas concept, in absence of specific incentives. The reference scenario favors a traditional 
balancing system based on gas turbines, both from the economic and technical point of view. High probabilities of reducing the effects of errors in day-ahead wind power production planning are achieved (in many cases above 90\%), allowing to contribute to the goal of the TSO to make the wind power generation system more stable.

Nevertheless, the convenience of installing electrolysis balancing systems could be achieved by a more favorable economic scenario. Although a strong reduction in investment costs for EL systems (we considered a target value of $270 € / \mathrm{kW}$ ) seems not sufficient alone to reach parity with gas turbine systems, in case it combines with favorable energy market conditions or with incentives ("green-gas" or carbon taxes), better economic balances are reached with a remarkable amount of power-to-gas power (up to about $6 \%$ of the wind park power). Moreover, in this work we considered a conservative efficiency level for the EL system (60\%), which could be offset by future technological evolution, and we assumed only the market option of hydrogen injection in the natural gas grid without delivery to any specific final user; as a consequence, the market price of the hydrogen has been set equal to the one of natural gas, although with possible incentives. In cases where hydrogen is produced, stored and distributed for specific applications like refueling stations for hydrogen vehicles, its final value could be different and the expected revenue of the investment would be larger.

From the energy balance point of view, both EL and GT solutions can improve the fraction of wind energy recovered. However, despite the curtailed wind energy is lower in presence of the electrolysis balancing system, the internal losses of the electrolyzers contribute somewhat in reducing the portion of wind energy actually exploited.

Finally, an aspect which favors the power-to-gas technology is the environmental impact: electrolysis based systems lead to a neutral balance of $\mathrm{CO}_{2}$ emissions, whereas the gas turbines add sig-

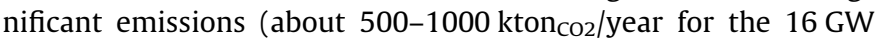
wind park considered). The study considers both emissions variations due to the balancing system itself and the effect on the whole generation park, therefore penalizing the relatively low efficiency gas turbine technology with respect to the reference combined cycle one.

In conclusion, this study shows that reasonable conditions exist in which a power-to-gas balancing system can be economically feasible. In addition to the necessary cost reduction of electrolysis systems, the main driving forces are the high ratio between the natural gas and electricity prices and the $\mathrm{CO}_{2}$ emissions cost.

\section{References}

[1] IEA (International Energy Agency), Harnessing variable renewables: A guide to the balancing challenge. Paris (France): OECD/IEA; 2011, p. 234.

[2] Hohmeyer $\mathrm{OH}$, Bohm S. Trends toward $100 \%$ renewable electricity supply in Germany and Europe: a paradigm shift in energy policies. Wiley Interdiscip Rev Energy Environ 2015;4(1):74-97.

[3] IEA (International Energy Agency). ETP - Energy Technology Perspectives 2012. Paris (France): OECD/IEA; 2012, p. 690.

[4] Denholm P, Hand M. Grid flexibility and storage required to achieve very high penetration of variable renewable electricity. Energy Policy 2011;39(3):181730.

[5] Franco A, Salza P. Strategies for optimal penetration of intermittent renewables in complex energy systems based on techno-operational objectives. Renew Energy 2011;36(2):743-53.

[6] Balling L. Flexible future for combined cycle. Modern power systems Dec-2010.

[7] Balling L. Fast cycling and rapid start-up: new generation of plants achieves impressive results. Modern power systems Jan-2011.

[8] DiCampli J, Schulke W. Grid stability: gas turbines for primary reserve, GT2013-94466. In: Proceedings of the ASME TurboExpo. San Antonio, Texas (USA); June 2013.

[9] Díaz-González F, Sumper A. A review of energy storage technologies for wind power applications. Renew Sustain Energy Rev 2012;16(4):2154-71.

[10] Beaudin M, Zareipour H, Schellenberglabe A, et al. Energy storage for mitigating the variability of renewable electricity sources: an updated review. Energy Sustain Dev 2010;14(4):302-14.
[11] Toledo OM, Oliveira Filho D, Diniz ASAC. Distributed photovoltaic generation and energy storage systems: a review. Renew Sustain Energy Rev 2010;14(1):506-11.

[12] DOE, DOE Global Energy Storage Database. <http://www. energystorageexchange.org/projects>. [accessed .08.14].

[13] Pearre NS, Swan LG. Technoeconomic feasibility of grid storage: mapping electrical services and energy storage technologies. Appl Energy 2015;137: 501-10.

[14] Boicea VA. Energy storage technologies: the past and the present. Proc IEEE 2014;102(11):1777-94.

[15] Lako P, Noord M, Eder H, et al. Hydropower development with a focus on Asia and Western Europe. Overview in the framework of VLEEM 2," ECN Policy Studies/Verbundplan, Report ECN-C-03-027, 2013. <https://www.ecn.nl/ publications/BS/2003/ECN-C-03-027>. [accessed .08.14].

[16] Gimeno-Gutiérrez M, Lacal-Arántegui R. Assessment of the European potential for pumped hydropower energy storage potential. JRC Scientific and policy reports; 2013, p. 74.

[17] IEA (International Energy Agency). Technology Roadmap - Hydropower. Paris (France): OECD/IEA; 2012.

[18] Crotogino F, Mohmeyer K-U, Scharf R. Huntorf CAES: more than 20 years of successful operation. Orlando, Florida (USA); 2001.

[19] Dresser-Rand. Compressed Air Energy Storage (CAES). <http://www. peterbrotherhood.co.uk/literature/general/85164-10-CAES.pdf>. [accessed .02.15]

[20] Stolten D. Hydrogen for road transportation - a pathway to renewable energy. In: Keynote 4 - Proceedings of ICAE 2014. Taiwan; 2014.

[21] Bullis K. Germany and Canada Are Building Water Splitters to Store Energy. MIT Technology Review, 2014. <http://www.technologyreview.com/news/ 530331 /germany-and-canada-are-building-water-splitters-to-storerenewable-energy/>. [accessed .02.15].

[22] Iskov H, Rasmussen N. Global screening of projects and technologies for Power-to-Gas and Bio-SNG. Danish Gas Technology Centre, Horsholm, Report 739-27, 2013. <http://www.dgc.eu/sites/default/files/filarkiv/documents/ R1307_screening projects.pdf $>$. [accessed .07.14]

[23] Robb D. Coping with wind and solar. Turbomach Int 2010;51(6):22-7.

[24] Ratliff P. The renewables effect on gas turbines: wind, while carbon-free, presents new challenges as it grows as a source of electricity in the U.S. Turbomach Int 2009;50(6):22-5.

[25] Guandalini G, Campanari S, Romano MC. Comparison of gas turbines and power-to-gas plants for improved wind park energy dispatchability. GT2014-26838. In: Proceedings of ASME Turbo Expo 2014. Duesseldorf (Germany); June 2014.

[26] Gahleitner G. Hydrogen from renewable electricity: an international review of power-to-gas pilot plants for stationary applications. Int J Hydrogen Energy 2013;38(5):2039-61.

[27] Bajohr S, Götz M, Graf F, et al. Storage of renewable electric energy in the natural gas infrastructure. GWF-Gas Erdgas 2011:200-11.

[28] E.ON, E.ON power-to-gas pilot unit in Falkenhagen. [accessed January 2015].

[29] INGRID Project. <http://www.ingridproject.eu/>. [accessed .08.14].

[30] GRHYD Project. <http://www.gdfsuez.com/en/gdf-suez-at-the-center-of-thenational-debate-on-energy-transition/power-to-gas-an-innovative-solution/ the-grhyd-demonstration-project/>.

[31] GRIDGAS Project. <http://www.gridgas.co.uk/>.

[32] Sterner M, Jentsch M, Holzhammer U. Energiewirtschaftliche und ökologische Bewertung eines Windgas-Angebotes. Fraunhofer Institut für Windenergie und Energiesystemtechnik (IWES). Kassel (Germany); 2011.

[33] IEA (International Energy Agency). Gas Medium-Term Market Report 2012. Paris (France): OECD/IEA; 2012, p. 168.

[34] IEA (International Energy Agency). Renewable energy Medium-term Market Report 2012. Paris (France): OECD/IEA; 2012, p. 182.

[35] Altfeld K, Pinchbeck D. Admissible hydrogen concentrations in natural gas systems. Gas Energy 2013(3):12.

[36] NATURALHY European Project (FP6), Preparing for the hydrogen economy by using the existing natural gas system as a catalyst - Final Report. Report SES6/ CT/2004/502661, 2010. <www.naturalhy.net>.

[37] Wagner M, Ballerstedt $\mathrm{H}$. Influence of biomethane and hydrogen on the microbiology of underground gas storage (Literature study). DGMK Project, Report 756, 2013.

[38] Bonzani F. V94.3A Special application: fuelling hydrogen enriched natural gas. In: Proceedings of PowerGen 2008. Milan (Italy); June 2008.

[39] Wind T, Güthe F, Syed K. Co-firing of hydrogen and natural gases in lean premixed conventional and reheat burners (Alstom GT26), GT2014-25813. In: Proceedings of ASME Turbo Expo 2014. Duesseldorf (Germany); June 2014.

[40] Guandalini G, Colbertaldo P, Campanari S. Dynamic quality tracking of natural gas and hydrogen mixture in a portion of natural gas grid, ID \#317. In: Proceedings of ICAE 2015. Abu Dhabi (United Arab Emirates); March 2015.

[41] Hu E, Huang Z, He J, et al. Experimental and numerical study on laminar burning characteristics of premixed methane-hydrogen-air flames. Int J Hydrogen Energy Jun. 2009;34(11):4876-88.

[42] Brower M, Petersen EL, Metcalfe W, et al. Ignition delay time and laminar flame speed calculations for natural gas/hydrogen blends at elevated pressures. J Eng Gas Turbines Power 2013;135(2):021504.

[43] Gazzani M, Chiesa P, Martelli E, et al. Using hydrogen as gas turbine fuel: premixed versus diffusive flame combustors. J Eng Gas Turbines Power 2014;136(5):051504. 
[44] Rivarolo M, Magistri L, Massardo aF. Hydrogen and methane generation from large hydraulic plant: thermo-economic multi-level time-dependent optimization. Appl Energy 2014;113:1737-45.

[45] Burkhardt M, Busch G. Methanation of hydrogen and carbon dioxide. Appl Energy 2013;111:74-9.

[46] Energy Economics Group (EEG), Development of regional and Pan-European guidelines for more efficient integration of renewable energy into future infrastructure 'SUSPLAN' - Synthesis of Results from the Regional Scenario Studies. SUSPLAN FP7 Project, Report FP7-218960-D2.10, 2010. <www. susplan.eu>.

[47] Associazione Nazionale Energia del Vento (ANEV). Italian wind potential, 2007, <www.anev.org>.

[48] Holttinen H. Hourly wind power variations in the Nordic countries. Wind Energy 2005;8(2):173-95.

[49] Holttinen H, Meibom P, Orths A, et al. IEA Wind Task 25 - Design and operation of power systems with large amounts of wind power - Final report. VTT Technical Research Centre of Finland; 2006.

[50] Gas Turbine World Handbook, no. 30. Pequot Publishing; 2013.

[51] Jensen JO, Jensen SH, Tophoj N, et al. Pre-investigation of water electrolysis. KI DTU, Riso DTU, DONG ENergy, Report PSO-F\&U 2006-1-6287, 2008. <http:// energinet.dk/SiteCollectionDocuments/Danskedokumenter/Forskning-PSOprojekter/6287-Elektrolysevedover100gr.C.pdf>. [accessed .08.14]

[52] Hocevar S, Summers W. Hydrogen production. In: Leon A, editor. Hydrogen technology. Springer; 2008. p. 15-79.

[53] Ursua A, Gandia L, Sanchis P. Hydrogen production from water electrolysis: current status and future trends. Proc IEEE 2012;100(2):410-26.
[54] Marini S, Salvi P, Nelli P, et al. Advanced alkaline water electrolysis. Electrochim Acta 2012;82:384-91.

[55] Farmer R. 30MW-class L30A gas turbine rated at over $41 \%$ efficiency. Gas Turbine World 2012;42(4):14-7.

[56] Kawasaki. Kawasaki Gas Turbine Generator Sets; 2010

[57] General Electric (GE). Interpretation of GE LM6000 Engineering Model Results for Part Load Cases; 2004.

[58] General Electric (GE). New High Efficiency Simple Cycle Gas Turbine - GE's LMS $100 ; 2004$.

[59] Hoeft R, Gebhardt E. Heavy duty gas turbine operating and maintenance considerations. GE Power Systems, Report GER-3620G; 2000.

[60] Brooks FJ. GE gas turbine performance characteristics. GE Power Systems, Report GER-367H; 2000.

[61] Silva P, Campanari S, Macchi E, et al. Optimization of the managing strategy of a cogenerative power park in a liberalized market, GT2004-53744. In: Proceedings of ASME Turbo Expo 2004. Wien (Austria); June 2004.

[62] Scholz C. Gas turbine operational flexibility - siemens perspectives. GT2014-27390. In: Proceedings of ASME Turbo Expo 2014 - Panel. Duesseldorf (Germany); June 2014

[63] Bonzani F. Improving combined cycle flexibility: design and operating experience, GT2014-27391. In: Proceedings of ASME Turbo Expo 2014 -Panel. Duesseldorf (Germany); June 2014

[64] Bertuccioli L, Chan A, Hart D, et al. Study on development of water electrolysis in the EU; 2014.

[65] ITM Power, Thuga group's P2G plant exceeds expectations. Press Release. $<$ http://www.itm-power.com/news-item/thuga-groups-p2g-plant-exceedsexpectations $>$. [accessed .02.15]. 